University of Windsor

Scholarship at UWindsor

Sociology, Anthropology, and Criminology

Department of Sociology, Anthropology and Publications

Criminology

Winter 2008

\title{
Effects of the criminalization of HIV transmission in Cuerrier on men reporting unprotected sex with men
}

\author{
Barry D. Adam \\ University of Windsor \\ Richard Elliott \\ Canadian HIV/AIDS Legal Network \\ Winston Husbands \\ Ontario HIV Treatment Network \\ James Murray \\ Ontario Ministry of Health and Long-Term Care \\ John Maxwell \\ AIDS Committee of Toronto
}

Follow this and additional works at: https://scholar.uwindsor.ca/socanthpub

Part of the Anthropology Commons, Criminal Law Commons, Other Public Health Commons, and the Sociology Commons

\section{Recommended Citation}

Adam, Barry D.; Elliott, Richard; Husbands, Winston; Murray, James; and Maxwell, John. (2008). Effects of the criminalization of HIV transmission in Cuerrier on men reporting unprotected sex with men. Canadian Journal of Law and Society, 23 (1-2), 137-153.

https://scholar.uwindsor.ca/socanthpub/17

This Article is brought to you for free and open access by the Department of Sociology, Anthropology and Criminology at Scholarship at UWindsor. It has been accepted for inclusion in Sociology, Anthropology, and Criminology Publications by an authorized administrator of Scholarship at UWindsor. For more information, please contact scholarship@uwindsor.ca. 


\section{Effects of the criminalization of HIV}

\section{transmission in Cuerrier on men}

\section{reporting unprotected sex with men}

Barry D Adam ${ }^{1}$, Richard Elliott ${ }^{2}$, Winston Husbands ${ }^{3}$, James Murray ${ }^{4}$, and John Maxwell ${ }^{5}$

Running head: Effects of criminalization of HIV transmission or exposure

Review of proofs:

Prof Barry D Adam, Dept of Sociology \& Anthropology, University of Windsor, Windsor, Ontario N9B 3P4. Voice: 519-253-3000 ext 3497, Fax: 519-971-3621, E-mail: adam@uwindsor.ca

\footnotetext{
${ }^{1}$ Dept of Sociology and Anthropology, University of Windsor, Windsor, Ontario

${ }^{2}$ Canadian HIV/AIDS Legal Network, Toronto, Ontario

${ }^{3}$ Research and Program Development, AIDS Committee of Toronto, Toronto, Ontario

${ }^{4}$ AIDS Bureau, Ontario Ministry of Health and Long-Term Care, Toronto, Ontario

${ }^{5}$ Special Projects, AIDS Committee of Toronto, Toronto, Ontario
} 


\begin{abstract}
This paper reports on the perceptions and practices of men who have frequent unprotected sex with men in a socio-legal environment defined by the 1998 decision of the Supreme Court of Canada in $R$. v. Cuerrier. HIV-positive people are increasingly finding themselves in court since Cuerrier and many are trying to take account of legal reasoning in their own conduct. The judicial construction of behaviour likely to transmit HIV relies on a set of presumptions concerning individual responsibility, rational and contractual interaction, and consenting adults that raise a series of ambiguities and uncertainties among HIV-positive people attempting to implement them in everyday life. While some express support for the reasoning in Cuerrier, others struggle with practical dilemmas in sexual interaction, and a minority strand of ethical reasoning advances a "buyer beware" principle. This latter view occurs in a social environment where HIV-positive people experience strong disincentives to disclose in the face of potential rejection or discrimination once their sero-status is known. Examination of the social consequences of Cuerrier raises questions about the viability of relying on the enforcement of disclosure, through threat of criminal prosecution, as an effective method of HIV prevention, especially when most practical, day-to-day HIV prevention occurs when safer sex is practised consistently regardless of disclosure.
\end{abstract}


In recent years, a rising number of cases concerning exposure to, or transmission of, HIV have been entering the Canadian court system. Accumulating case law, and the Supreme Court of Canada decision in R. v. Cuerrier, [1998] 2 S.C.R 371, have begun to specify the kinds of conduct that may be vulnerable to criminal prosecution, setting a standard of requiring HIV-positive people to disclose their sero-status in advance of sexual activity posing a "significant risk" of HIV transmission. These actions of the judiciary, in effect, make the court system one of the actors in a larger field composed of community groups, AIDS service organizations, public health, medicine, research, and government, all working toward reducing rates of HIV transmission. The courts' construction of disclosure of HIV sero-status in a context of legal argumentation concerning consent, fraud, and individualized harm as they relate to criminal law, enters into a social field in effect advancing disclosure as a central component in HIV prevention. These court decisions implicitly endorse a model of human behaviour that holds that HIVpositive people can and should assume the responsibility of warning others of the potential for infection, and that prospective partners will act appropriately to avoid infection once informed of that potential.

The actions of the courts engage a longer history of a politics of "innocence" and "blame" regarding HIV transmission. In the early years following the identification of AIDS in 1981, several panic-driven proposals to quarantine, criminalize, or restrict HIV-positive people circulated in the public sphere, in some instances resulting in punitive public policies. By the mid-1990s, a more equilibrated response emerged that Jeffrey Weeks summarizes as

the growth of a sense of mutual responsibility among those most at risk. This was a direct result of the broadening of the arena of private space through the construction of sexualized 
communities where the possibilities of safer sexual behaviour could be easily discussed and developed [...]. In practice, this meant the elaboration of sexual etiquette in which the individual actors could attempt not so much to eliminate all risk of coming into contact with HIV, but rather to seek a balance between risk and trust in sexual contacts by a pragmatic adoption of "safer sex".6

This policy of mutual responsibility, reinforced through messages promoted by AIDS service organizations and public health agencies, stresses that HIV prevention through safer sex is the responsibility of both HIV-negative and HIV-positive people, recognizes that a significant amount of HIV transmission involved people unaware of their HIV status, and does not rely on HIV-positive people to disclose their sero-status for effective prevention. In recent years, court decisions have re-opened some of these questions concerning responsibility and effective prevention. It might be argued that the courts have been brought into the process at moments when practices of mutual responsibility are at issue as complainants seek redress for exposure to HIV. At the same time, the trend toward reliance on disclosure, institutionalized by Cuerrier, has in turn raised new questions about the degree to which the onus of responsibility may be shifting "back" toward HIV-positive people, undermining the "mutual responsibility" principle of the 1990s.

This study reports on the perceptions and experiences of a set of men who have unprotected sex with men most or all of the time. They are, then, a set of people for whom Cuerrier and related court decisions have particular salience; they are, as well, of particular interest in the study of HIV prevention

6 Jeffrey Weeks, Invented Moralities 137 (New York: Columbia University Press, 1995). 
since they are considerably less likely to practise protected intercourse compared to the men around them. Indeed, it is important to bear in mind that this set of men is unrepresentative of gay and bisexual men as whole, the majority of whom practise protected sex most or all of the time.7 Rather they are drawn from a small subset of men reporting recent unprotected anal intercourse. These 34 men were interviewed to gain insight into the motivations and decision-making processes that go into encounters of un/protected sex. As the final question in an interview process when study participants spoke at length about anal sex without condoms, "bareback sex," sex and drugs, and responsibilities of HIVpositive and negative partners, they were asked, "Have you heard of the Cuerrier decision?" For those who had not heard of it, the interviewer stated,

In the Cuerrier decision, the Supreme Court ruled that HIV-positive people must disclose their sero-status in a sexual encounter. What is your view of this?

This paper focuses particularly on the answers to these questions to examine how the courts' reasoning may be received, adapted, or resisted by a population potentially vulnerable to its application, and to provide insight into the effects of the judicial construction of HIV on risk management in everyday life.

\section{The Canadian legal context}

The first Canadian cases of criminal prosecution of HIV-positive people for conduct that transmitted, or risked transmitting, HIV arose in the late 1980s, and continued to accumulate slowly but steadily in the early 1990s, as police and prosecutors laid a variety of different charges under various Criminal Code provisions in the face of legal uncertainty about which provisions were best suited to, or capable of,

7 Ted Myers et al, Ontario Men's Survey (Toronto 2004); Barry D Adam et al, Risk Management in Circuits of Gay and Bisexual Men (Toronto 2007). 
being used to secure convictions. A significant number of these early cases resulted in guilty pleas, meaning limited judicial analysis, even at the trial court level, of the legal questions raised about applying certain offences to deal with actual or risked transmission of HIV through consensual sex. Consequently, the uncertainty about the clear legal applicability of some of these provisions persisted. In 1998, the first such case reached the Supreme Court of Canada, resulting in one of the first decisions anywhere on this subject from a country's highest court. In $R$. v. Cuerrier, 8 the Court was faced with the question of whether a man originally charged in 1992 for unprotected vaginal sex with two women without disclosing his HIV-positive status could, as a matter of law, be convicted of the offence of aggravated assault, as the sexual encounters were otherwise consensual. The original acquittal, which had been upheld on appeal, was appealed further by the prosecution to the Supreme Court. A panel of seven judges heard the case, and while they issued three separate sets of reasons, each of which took a different approach, they were unanimous in concluding that non-disclosure of HIV-positive status could nullify a partner's consent to sex, thereby rendering the physical contact an assault as a matter of law. In the case of non-disclosure of HIV infection, the Court was satisfied that the assault could "endanger the life" of the sexual partner, and therefore could amount to an aggravated assault as defined in the Criminal Code.

The majority (and hence most significant) judgment clearly stated that there would be a legal duty to disclose known HIV infection to a sexual partner in the circumstance where there is a "significant risk of serious bodily harm." It accepted that infection with HIV would constitute a serious bodily harm, and also suggested that it is possible other sexually transmitted infections might meet this standard as well,

8 [1998] 2 S.C.R 371. 
although it did not specify which ones. The majority was also clear to state that, in the absence of a "significant" risk of transmission, there is no duty, under Canada's criminal law as it stood (and still stands), to disclose, and even suggested that "careful use of condom might be found to so reduce the risk of harm that it could no longer be considered significant so that there might not be either [harm or risk of harm]."9

In the result, the Supreme Court's decision in Cuerrier resolved at least some legal uncertainty: it has clarified that, as a matter of Canadian criminal law, a person who knows he or she is HIV-positive can be convicted of aggravated assault (or the parallel offence of aggravated sexual assault) if he or she engages in unprotected vaginal sex without first disclosing this fact to his or her partner. Given available evidence about levels of risk of transmission, it is safely assumed that unprotected anal sex would also meet the "significant risk" threshold if vaginal sex does. Not surprisingly, since the Cuerrier judgment was released in 1998, there has been an increase in the number of observed prosecutions - and, in recent years, a significant surge in the rate of new prosecutions, based on initial assessments of data collected by the Canadian HIV/AIDS Legal Network, which has been tracking such reports since the early 1990s in the media and in electronic legal research databases, as well as through contacts with individual accused and with lawyers handling such cases. As of this writing (August 2008), there have been approximately 83 HIV-positive people (73 men, 10 women) charged in Canada for situations of sexual exposure to, or transmission of, HIV to one or more complainants; of those, 66 of those cases have come after 1998, the year of the Cuerrier judgment, and in the majority of cases, the offence most

9 Richard Elliott, After Cuerrier: Canadian Criminal Law and the Non-Disclosure of HIV-Positive Status (Montreal: Canadian HIV/AIDS Legal Network, 1999). 
commonly laid, post-Cuerrier, is aggravated assault or aggravated sexual assault. It is impossible to track, with absolute precision across the country, the total number of such cases, given where and how data are collected at the level of such charges being laid in the courts, that the media may not report every case, and that legal databases will not necessarily capture every case across the country depending on its disposition. The increase in the number of (known) prosecutions has, not surprisingly, been matched by greater media coverage of such cases. Sentences in such cases have varied widely, from 1 to 18 years; in addition to other factors, the number of complainants, and whether there was infection as opposed to simply exposure, obviously inform sentences imposed following a guilty plea or conviction. An initial review of the known cases suggests, however, an increase in the severity of sentences in recent years, although this requires more careful, detailed analysis to control for other variables.

These cases have provoked considerable discussion among people living with HIV/AIDS (or at least certain populations), among those working in the field of public health, and among AIDS service organizations (ASOs) and other service agencies, as well as among health care professionals and others providing HIV testing, counselling, and care services. A variety of educational and information resources have been produced for various audiences to help people understand the state and significance of the law, but uncertainty, confusion, and concern remain, as evidenced not least by the continuing stream of inquiries to ASOs and to other organizations (e.g., HIV \& AIDS Legal Clinic Ontario, Canadian HIV/AIDS Legal Network) from HIV-positive people, from service-providers, and from the media in conjunction with new cases arising. In addition, it remains uncertain, as a matter of law, just how far the ambit of criminalization of HIV non-disclosure extends. 
One of the primary unanswered questions is whether there remains a legal duty to disclose known HIVpositive status in the event of condom use (or other "safer sex" approaches that avoid the level of HIV transmission risk associated with unprotected vaginal or anal sex). In the course of the Cuerrier case, a number of AIDS organizations were granted official intervener status and made submissions to both the B.C. Court of Appeal and the Supreme Court of Canada on a variety of broader, public policy considerations about the use of criminal law to prosecute HIV-positive people for non-disclosure. It was apparent during the course of those proceedings that there is a distressing dearth of evidence, not only in Canada but worldwide, about the understanding of criminalization of HIV exposure or transmission by HIV-positive people and others, and of the impact of said criminalization. The majority opinion of the Supreme Court of Canada was quick to dismiss, for want of hard data, the concern of AIDS organizations that such prosecutions could create an additional disincentive to HIV testing or a barrier to accessing HIV services (e.g., counselling about risk reduction). Yet the Court was far less hesitant in accepting the proposition that criminalizing sex without disclosure would serve an HIV prevention function and protect public health because of its deterrent effect on HIV-positive people who might otherwise put sexual partners at risk without their knowledge - even though there is just as little evidence to support this claim. As a result, public policy, as it manifests in the courts' and prosecutors' interpretation of the criminal law, is being made largely in an evidentiary vacuum, a situation that this study begins to address.

\section{Research on disclosure}

Canadian courts have made disclosure of HIV status a central requirement in sexual interactions in certain circumstances on the presumption that disclosure provides fair warning to prospective partners 
of the potential for infection, that people will take steps to avoid infection once they have been informed, and that the legal enforcement of a norm of disclosure will presumably have a meaningful effect on reducing the HIV epidemic. The basic reasoning underlying cases such as Cuerrier, or similar principles, do receive some documented support from many HIV-positive people themselves. In October, 2003, the website of the popular U.S. magazine for HIV-positive people, Poz, reported that 70\% of its primarily HIV-positive readership ( $N=631)$ voted "yes" to the question, "Should HIVers who have unprotected sex without disclosing their status face criminal charges?" (October 2003:7). Several HIVprevention interventions directed toward HIV-positive people also take disclosure as a fundamental component of risk reduction.10

Nevertheless, disclosure is not without difficulty as a leading public policy in HIV prevention. First of all, disclosure has very different implications for HIV-positive and HIV-negative people. A survey of Australian men who have sex with men reports that

forty per cent of HIV positive men expected their partners to disclose whereas $80 \%$ of HIV negative men expected such disclosure. By contrast, $84 \%$ of negative men, as opposed to $12 \%$ of positive men, also stated that they sometimes or (mostly) always avoided having sex with HIV positive men. The different disclosure expectations between positive and negative men set the sexual stage for diametrically opposed assumptions in precisely the situations where HIV transmission occurs. Moreover, the expectation and avoidance configurations set up a double bind for positive men.11

10 Gerjo Kok, "Targeted Prevention for People with HIV/AIDS" (1999) 36 Patient Education and Counseling 239; Seth Kalichman et al, "Effectiveness of an Intervention to Reduce HIV Transmission Risks in HIV-Positive People" (2001) 21(2) American Journal of Preventive Medicine 84; Thomas Patterson, William Shaw and Shirley Semple, "Reducing the Sexual Risk Behaviors of HIV+ Individuals" (2003) 25(2) Annals of Behavioral Medicine 138, 138; Seth Kalichman, David Rompa and Marjorie Cage, "Group Intervention to Reduce HIV Transmission Risk Behavior Among Persons Living with HIV/AIDS" (2005) 29(2) Behavior Modification 256.

11 Gary Smith and Paul Van de Ven, Reflecting on Practice 18 (Sydney: National Centre in HIV Social Research, 2001). 
Some HIV-positive people have reported that

rejection from partners following disclosure took many forms, including refusal to have sex, unwillingness to engage in particular sex practices, emotional distancing, abrupt or longer term relationship dissolution, and even (although rarely) acts of violence.12

Though this kind of reaction is relatively infrequent, and indifference to and acceptance of HIV-positive status are more common, the threat of rejection raises the disclosure stakes considerably. A minority of HIV-positive men are willing to announce their sero-status upfront and every time, but for many others, it is a process of testing the waters or dropping hints.13 Some

conveyed their serostatus to their partners by mentioning or exhibiting various embodiments of their serostatus: that they received disability payments, worked in HIV/AIDS services, lived in an HIV/AIDS residence, or had visible HIV/AIDS symptoms.14

Similar strategies are employed by men living with HIV in Toronto15 and Ohio.16 Those who disclose consistently

reported significantly higher levels of self-efficacy to disclose, intentions to disclose, and perceived responsibility to protect others from infection, increased feelings of connection to other HIV-positive men, stronger beliefs about HIV/sexually transmitted disease transmission

12 Michael Stirratt, "I Have Something to Tell You", in (Perry Halkitis, Cynthia Gómez and Richard Wolitski eds) HIV+Sex 101, 103 (2005).

13 Robert Klitzman and Ronald Bayer, Mortal Secrets 51 (Baltimore: Johns Hopkins University Press, 2003).

14, I Have Something to Tell You at 114.

15 Barry D Adam, "Constructing the Neoliberal Sexual Actor" (2005) 7(4) Culture, Health \& Sexuality $333,340$.

16 Julianne Serovich et al, "Methods of HIV Disclosure by Men Who Have Sex with Men to Casual Sexual Partners" (2005) 19(12) AIDS Patient Care and STDs 823. 
and viral consequences of unprotected sex, [and] lower levels of hedonistic assumptions than either inconsistent or non-disclosers.17

Disclosure can also be enmeshed in the power dynamics of advantage and disadvantage. While at least one study finds that women disclose to partners more often than men,18 a substantial research literature on women and HIV points toward the difficulty that many women experience in disclosing to men, especially when they are dependent on them.19 Similar dynamics are likely at work among those who feel disadvantaged because of age, attractiveness, or ethno-cultural background. Disclosure is much more common with better-known partners, less so with casual partners. 20 Disclosure is not easy and there is considerable evidence that HIV-positive men are over-represented in quick-sex settings

17 Jeffrey Parsons et al, "Consistent, Inconsistent, and Non-Disclosure to Casual Sexual Partners Among HIV-Seropositive Gay and Bisexual Men" (2005) 19(Supplement 1) AIDS, S91-92.

18 Kenrik Duru et al, "Correlates of Sex Without Serostatus Disclosure Among a National Probability Sample of HIV Patients" (2006) 10(5) AIDS and Behavior 495.

19 Nancy Stoller, Lessons from the Damned (New York: Routledge, 1998); Linda Manfrin-Ledet and Demetrius Porche, "The State of the Science" (2003) 14(6) Journal of the Association of Nurses in AIDS Care 56; Karolynn Siegel, Helen-Maria Lekas and Eric Schrimshaw, "Serostatus Disclosure to Sexual Partners by HIV-Infected Women Before and After the Advent of HAART" (2005) 41(4) Women \& Health 63.

20 Gary Marks and Nicole Crepaz, "HIV-Positive Men's Sexual Practices in the Context of Self-Disclosure of HIV Status" (2001) 27(1) Journal of Acquired Immune Deficiency Syndromes 79; Trevor Hart et al, "Partner Awareness of the Serostatus of HIV-Seropositive Men Who Have Sex with Men" (2005) 9(2) AIDS and Behavior 155, 163; Sherry Larkins et al, "Methamphetamine-Dependent Gay Men's Disclosure of Their HIV Status to Sexual Partners" (2005) 17(4) AIDS Care 521, 527. 
precisely because disclosure can be avoided.21 In settings governed by non-verbal expectations, disclosure of sero-status is, not surprisingly, unusual.22

Disclosure as a prevention strategy, in the end, has several pitfalls: it presumes both prospective sex partners are certain of their sero-status, it tacitly transfers responsibility for safer sex to HIV-positive people, and raises the prospect of becoming involved in legal process.23 The belief that HIV-positive people invariably know their sero-status and will disclose may encourage HIV-negative people to be less consistent in practising safer sex and to expose themselves to greater risk. Robert Remis and colleagues estimate that as few as 64 percent of HIV-positive people in Ontario in fact know their sero-status.24 Disclosure is not necessarily associated with higher rates of protected sex among gay and bisexual men25 if only because most continue to practise safer sex most of the time without needing verbal communication to do so. Indeed consistent practice of safer sex usually does not require discussion and

21 Parsons and P Halkitis, "Sexual and Drug-Using Practices of HIV-Positive Men Who Frequent Public and Commercial Sex Environments" (2002) 14(6) AIDS Care 815, 823; Larkins et al, 17 AIDS Care at 526, Vicioso et al. 2005:17.

22 Cathy Reback, Sherry Larkins and Steven Shoptaw, "Changes in the Meaning of Sexual Risk Behaviors Among Gay and Bisexual Male Methamphetamine Abusers Before and After Drug Treatment" (2004) 8(1) AIDS and Behavior 87; Nicholas Sheon and G Michael Crosby, "Ambivalent Tales of HIV Disclosure in San Francisco" (2004) 58 Social Science \& Medicine 2105, 2111; Hart et al, 9 AIDS and Behavior; Stirratt, I Have Something to Tell You.

23 Chris Collins et al, Designing Primary Prevention for People Living with HIV (San Francisco 2000); Jane Simoni and David Pantalone, "HIV Disclosure and Safer Sex", in (Seth Kalichman ed) Positive Prevention 65 (2005).

24 Robert Remis et al, Report on HIV/AIDS in Ontario 2005 (Toronto 2007).

25 Marks and Crepaz, 27 Journal of Acquired Immune Deficiency Syndromes; Seth Kalichman et al, "HIV Transmission Risk Behaviours Among HIV-Positive Persons in Serodiscordant Relationships" (2002) 13 International Journal of STD \& AIDS 677, 681. 
proceeds without it.26 Those who decide, encounter to encounter, whether to disclose or not, and who then disclose inconsistently have higher rates of unprotected sex than those who consistently disclose or do not disclose. 27

As the above review indicates, there is an extensive body of research on the question of HIV disclosure, safer sex practices, and the relationship between the two. However, there is a dearth of evidence as to the impacts of criminalization of HIV exposure and transmission, including on HIV-positive people themselves, as an HIV prevention strategy (by penalizing non-disclosure to sexual partners in at least some circumstances), and on public health more broadly (e.g., on safer sex practices, HIV testing decisions, etc). Indeed, this was the case in 1998 when Cuerrier was heard by the Supreme Court of Canada. As noted above, the Court dismissed, for lack of evidence, concerns about the possible adverse public health consequences of over-extending criminalization, yet simultaneously accepted the proposition that the threat of criminal liability would deter HIV-positive people from engaging in sexual activity carrying a risk of HIV transmission without disclosing their serostatus, notwithstanding an equal lack of evidence on this point. Our initial scan of the literature, in English and French, and the familiarity of the investigators with that literature based on years of working on this issue, leads us to the conclusion that, while there has been extensive commentary and analysis in the legal literature on the question of criminalizing HIV exposure and transmission, there are few research studies that attempt to investigate the effects of such criminalization on everyday risk practices.

26 Benny Henriksson and Sven Månsson, "Sexual Negotiations", in (Han ten Brummelhuis and Gilbert Herdt eds) Culture and Sexual Risk 170 (1995).

27 Hart et al, 9 AIDS and Behavior; Limin Mao et al, "'Serosorting' in Casual Anal Sex of HIV-Negative Gay Men is Noteworthy and is Increasing in Sydney, Australia" (2006) 20(8) AIDS 1204, 945. 


\section{Methods}

A survey done at Toronto Pride 2005 asked men to indicate the venues and scenes they frequented, including whether they frequented "bareback" scenes and websites.28 Among the findings from that study was that men in bareback scenes and websites agreed 6.62 times ( $p \# .001)$ more often with the following statement than did other men with casual male partners in the survey:

I respect whatever the guy wants regardless of whether he is positive or negative. If he wants to use a condom, that's fine, and if he doesn't, that's fine too.

They agreed 5.87 times (p\#.001) more often with the statement:

If I lose my erection with a condom on, I prefer to have sex without it.

We set out, then, to recruit men to interview who agreed with either of these two statements as they strongly predicted involvement in bareback scenes and websites but did not always require respondents to identify with bareback as a term or identity. Men who agreed with one of the statements and who had not participated in another study within the last year were accepted for interview. In all, 34 men met the eligibility criteria: 10 responded to recruitment messages sent to men with Toronto-based profiles on popular gay websites, 6 volunteered as a result of referrals by those who had already been interviewed, 5 each responded to posters placed in the community and handbills in bars and baths associated with the bareback circuit, 3 referred to an advertisement they had seen in the gay press, and the rest did not recall or mention the recruitment route. Recruiting men who agreed with one or both of the statements proved to be effective in finding men who had unprotected sex most or all of the time; only one turned out to be maintaining a consistently safe practice (though with some difficulty). It is important to stress, then, that this sample of men is not indicative of gay and bisexual men in general,

28 Barry D Adam et al, "Circuits, networks, and HIV risk management" (Forthcoming) 20 (5) AIDS Education and Prevention 
nor of HIV-positive men, the majority of whom continue to practise protected sex most or all of the time.29

Participants in this study came from a variety of backgrounds as defined by age, education, income, and ethno-cultural origins. Most were HIV-positive ( $\mathrm{N}=24) ; 10$ were HIV-negative. The ages of study participants ranged from 22 to 60 , with most being in their $40 \mathrm{~s}(\mathrm{~N}=12)$ or $30 \mathrm{~s}(\mathrm{~N}=11)$. Educational levels ranged from less than high school to postgraduate and professional degrees; most $(N=20)$ had 1-4 years of post-secondary education. Income levels ranged from less than $\$ 10,000$ per year to more than $\$ 100,000$ per year. The largest income category $(\$ 10,000$ to $\$ 20,000$ per year) consisted of: 7 unemployed, 5 on disability or other pension, 4 students, and 3 retired. The median income of this group, then, was lower than the median income category of the broad-based Pride survey of $\$ 40,000$ to $\$ 49,999$ per year.30 Study participants indicated their ethno-cultural background to be: 13 British, 9 Canadian, 5 French, 11 other European, 3 Aboriginal, 3 African or Caribbean, and 4 Asian, Middle Eastern, or Latin American. (More than one ethnic category could be selected by a participant.) The study proposal was reviewed in accord with the Tri-Council Policy Statement: Ethical Conduct for Research Involving Humans of Canada. Study participants who wished to be informed of the results of the study, and left contact information, were subsequently notified once the study results were posted to the website of the AIDS Committee of Toronto.

An advisory committee consisting of representatives of community groups of LGBT youth, south Asians, Caribbean people, bisexuals, older men, transmen, as well as representatives from local bathhouses and websites, met throughout the research process to discuss the development of the questionnaire,

29 Myers et al, Ontario Men's Survey; Adam et al, Risk Management in Circuits of Gay and Bisexual Men. 30 Adam et al, Risk Management in Circuits of Gay and Bisexual Men at 39. 
recruitment of participants, interpretation of results, and recommendations for the application of results in the HIV prevention work of local AIDS service organizations.

An honorarium of $\$ 30$ was provided to each participant. Interviews were transcribed, then examined for interactive processes and circumstances involved with instances of unprotected sex. Common discourses were gathered together into themes using NVivo7.

\section{Support for criminalizing non-disclosure of HIV-positive status}

The 34 men in the study showed a wide range of views on the merits of the current directions taken by the courts. Eight ( 3 of 10 HIV-negative; 5 of 24 HIV-positive) expressed clear support for the legal requirement to disclose especially if having sex without condoms. This is particularly the case in an HIVnegative man who was attempting to identify other HIV-negative men for sex without condoms.

I do think that a person who is HIV-positive and fucks people and comes in them without telling them, that is committing a serious breach of ethics.... It's fair of me to give you the information. I think it's fair and if the Supreme Court has ruled that it's also compulsory, then so be it, it's compulsory. 002 HIV-

Obligatory disclosure did, as well, find support among some HIV-positive men.

I don't think it's a privacy issue when you're going around sleeping with people-right? - and possibly putting them at risk-right? .... I think if you're going around sleeping with people and you don't tell them and they end up finding out, they have the right to have you charged. 008 $\mathrm{HIV}+$

And again,

Hell, if you're going to fuck somebody, if you accepted responsibility of fucking them, you know you better, you know, give them, you know, enough information. $016 \mathrm{HIV+}$

One HIV-positive man articulated an even higher standard of disclosure than that envisioned in Cuerrier by anticipating a need to disclose data that could have a bearing on the question of "re-infection" between HIV-positive partners. 
Well imagine me having 300,000 viral load and 2 counts on the CD4 and I want to make love with you and you're doing over 700 on your count and you're undetectable on your viral load and I want to have unsafe sex with you and I'm not going to tell you? That wouldn't be very fair to you--right?--or vice versa. $007 \mathrm{HIV+}$

Indeed for many HIV-positive people, risk management questions are not necessarily solved even with HIV-positive partners.31

\section{Disclosure problems in practice}

Though the expectation of disclosure of HIV-positive status is widespread, especially among HIVnegative people, the act of disclosure may not be so easily accomplished in everyday life. While HIVnegative men have little to say about disclosure of HIV status, as they have the luxury of experiencing it as no problem, HIV-positive men often talk at length about disclosure dilemmas and strategies. This informant, for example, figured his presence outside an AIDS service organization provided fair warning to a prospective partner.

We've never actually discussed it, but you know what I mean? I'm like, well he's seen me here on more than one occasion, you know, when he's walking by or whatever and he's probably not thinking I'm just hanging out here for the fun of it.

I: When you say here, you mean PWA [People With AIDS Foundation]?

Yeah.... You know, like l'll sometimes be outside having a cigarette in the front. [004] Some do manage to disclose forthrightly to every prospective sexual partner but the psychological costs may be high for people placed repeatedly in the situation of disclosing a status that risks rejection, deprecation, or hostility. As expressed by one study participant,

I had enough experiences of people reacting badly that I say I might as well just tell them right up front and if he runs off screaming in terror, then, like, away he goes.... but it's something that

31 Barry D Adam et al, "Risk Construction in Reinfection Discourses of HIV-Positive Men" (2005) 7(1) Health, Risk and Society 63. 
I find that I would prefer not to do and I would so prefer not to do it that I will actually steer myself clear of people where I might have to do it....I hate the idea of meeting somebody that is attractive to me and he seems really nice and is personable and seems to like me and then finding out that they're negative and then realizing that I'm probably not going to get involved with them. $003 \mathrm{HIV}+$

The expectation to disclose is felt keenly by many HIV-positive people who agonize about how best to do it in the face of an anticipated negative reaction.

It's never a light-hearted, you know, encounter with someone if he's got to have the big discussion....My experience has been even when l've played safe--that there was one individual I didn't tell and he wanted to see me again and, and although we had safe sex, he was incredibly disgusted and thought I was incredibly dishonest and, and wouldn't have anything to do with me anymore. $004 \mathrm{HIV}+$

There are, then, considerable real-world disincentives to carrying out the seemingly rational, contractual scenario presumed by the legal demand to disclose.

I just felt kind of dirty I guess by being rejected and knowing that that'll probably happen again has turned me off more. 034 HIV+

The HIV prevention policy promoted by AIDS service organizations for more than two decades has been to advise people that disclosure is a much less reliable means of avoiding HIV transmission than simply consistently practising safer sex. Indeed recent epidemiological research shows that, even a quartercentury after the first identification of AIDS, almost half of HIV transmission appears to be occurring from people who are themselves recently infected,32 suggesting that large numbers of people who are transmitting HIV may not be aware that they are HIV-positive. As a result, there tends to be widespread acceptance of the idea in gay communities that disclosure is not fundamental to effective HIV prevention. This informant articulates that norm and, indeed, deploys disclosure precisely because of its likelihood of breaking a potential sexual connection.

32 Bluma Brenner et al, "High Rates of Forward Transmission Events After Acute/Early HIV-1 Infection" (2007) 195 Journal of Infectious Diseases 951. 
I don't generally disclose that but if they insist on sex without condoms, then yeah I will....If I'm telling somebody that I'm HIV-positive for my own sake, it's usually to get out of the situation. It's usually to get away and to not have sex with them. $018 \mathrm{HIV+}$

\section{Caveat emptor without disclosure}

In this study, 7 study participants ( 6 of 24 HIV-positive; 1 of 10 HIV-negative) articulate a view contrary to the presumptions at play in the judgment of the majority of the Supreme Court of Canada in Cuerrier. Though only a minority view among gay men, and among HIV-positive men in particular, it is a view that carries the premises of individual responsibility, rational and contractual interaction, and consenting adults in quite a different direction.33 This view holds that HIV-positive people have no greater responsibility to prevent HIV transmission than anyone else and that Cuerrier-like decisions about legal liability inequitably minimize the responsibility of HIV-negative people in avoiding HIV transmission.

It takes two to tango.... People are not going to go around saying, "Oh I'm HIV-positive," you know, to every sex partner they have and...I don't think they should have to. 005 HIV+

Another expresses a similar viewpoint absolving HIV-positive people of a heightened responsibility in a sexual interaction and the inappropriateness of legal liability, yet nevertheless does disclose to his sexual partners.

I don't really agree with it because I agree we're all adults and everybody should automatically assume a person's positive, no matter what, and I don't think it should be up to the courts to decide or punish a person who doesn't tell their status because even a negative person could be positive and infect someone else and not know it....As a positive person myself, I just prefer to tell everyone just for the fact for the way I got it, because I just find it was really cold and mean for what he did to me and I wouldn't want to give this disease to anybody else that way. Like even my worst enemy I wouldn't wish that on. 021 HIV+

A similar ambivalence is evident in this narrative which attempts to reconcile de jure and de facto rationalities.

33,7 Culture, Health \& Sexuality. 
Increasingly there are court cases that uphold decisions that say that if you don't disclose your status you are liable. Do I agree with that? No, because I think everyone really should be in charge of their own health, but that said, if we all were, then probably there wouldn't really be that many positive people. $027 \mathrm{HIV}+$

Finally, another school of thought holds that it is not failure to disclose, but rather false disclosure, that should be the object of legal intervention.

I think if you're lying to someone, if they're saying, "Are you positive?" and you're saying, "No, I'm not," that's different than them not asking you and not telling. I think really people need to take responsibility for themselves and if you're having sex with someone you don't know really well, you should be wearing a condom if you're concerned about it, and if you're not concerned about it, then you should be aware that you've got the consequences to deal with, that you might get it. $022 \mathrm{HIV}+$

Another respondent struggles with competing principles, agreeing that false disclosure is impermissible while reaching for a no-fault view of HIV infection.

I think if a person is asked, they should tell the truth and if a person lies, then they should be liable. But I think that we're all adults here, especially if it's not somebody dealing with somebody who, say, is a lot younger.... suppose it would have been nice if whoever that person or those people were, you know, that I was infected by, it would have been nice if I'd known. I don't know. It's like a can of worms. It's hard.... I accept my responsibility for being HIVpositive. I don't necessarily blame it on somebody else.... I try not even to point a finger at myself and say it's my fault. It was one of those things that happened and it's not really a fault. 003 HIV+

\section{The prospect of legal intervention}

The rise of legal intervention into HIV transmission or exposure causes some consternation among seropositive people attempting to steer a course through the practicalities of HIV risk management. These anxieties centre around several issues: the vulnerability of HIV-positive people to criminal prosecution, particularly in the wake of the Cuerrier decision; how to know how much precaution is enough in the sexual engagement of partners of mixed sero-status; how to prove "responsible behaviour" in a possible he said/he said situation; and whether, in some relationships, disclosure could in fact heighten, rather 
than lessen, vulnerability to prosecution or the threat of prosecution down the road (e.g., as a means of coercion during a relationship or of retaliation following relationship breakdown).

The prospect of legal intervention raises the stakes in attempting to determine how high a level of safety in safer sex is enough.

I don't know whether it's illegal if I had sex with someone, but have safe sex and don't tell them, because the gray area of what's safe sex is there, you know. When I practise safe sex with someone, for me that's pretty much just anal sex or if it was oral, I wouldn't ejaculate in the person's mouth or anything like that, but I don't know where the law thing's different and whether they think you know. I wish I knew. $004 \mathrm{HIV}+$

Just where the boundaries of (legal) adequacy lie are not always easy to determine.

If I was to go out and have sex with someone, use a condom, and the condom broke and infected them that way, I'm not sure if the courts could find me guilty of putting my partner at significant high risk because I actually took precautions by wearing a condom. $009 \mathrm{HIV+}$

How to establish that (adequate) disclosure and consent have occurred in an encounter worries others.

I do worry that, you know, I might disclose to someone even before sex and then it becomes his word against mine later right and if I go to court ....I'd probably lose my job.... I know that a lot of people would lose respect for me. 006 HIV+

Another remarks,

You have to be really careful these days.... I would not jeopardize anybody and give them any chance at all in order to have me criminally charged for intentionally infecting them with HIV. That is a no-no and you can go to jail for that. $007 \mathrm{HIV+}$

Once disclosure has occurred and consent has been given, how much liability remains with HIV-positive people if an HIV-negative partner does not take the precautions presumed to be automatic by the disclosure doctrine in Cuerrier?

What if one that's negative makes a decision to... have sex without a condom, and then he gets infected and then it all comes back to me and then I'm charged? I'm in jail....so I'm really careful around that. $010 \mathrm{HIV+}$

In the end, some try to avoid HIV-negative partners altogether. 
I don't think I could date an HIV negative man. I don't think that would work-you know what I mean?-because there'll be too much pressure on me....You can go to prison for infecting someone with HIV. That's a big deal in my world. 034 HIV+

\section{Conclusion}

HIV-positive people are increasingly finding themselves in court since Cuerrier and many are trying to take account of legal reasoning in their own conduct. The judicial construction of behaviour likely to transmit HIV relies on a set of presumptions concerning individual responsibility, rational and contractual interaction, and consenting adults whereby potential sexual partners give fair warning to each other in a manner that allows (if not impels) informed consent to take place in advance of a sexual interaction.34 Legal discourses tend to instantiate a subject of HIV transmission consistent with dominant constructions of Western individualism, that is, the "calculating, rational, self-interested subject" that Barry Smart identifies as the paradigmatic subject of contemporary neoliberalism.35 Examination of this construction of a set of "thoughtful, actuarial subjects, gathering data and acting on the basis of 'fact'" 36 reveals this vision of human behaviour as something of an ideal with no easy fit with the day-to-day experiences and practices of sexual and romantic interaction. Legal precepts raise a series of ambiguities and uncertainties among HIV-positive people attempting to implement them in everyday life. The construction of risk scenarios in terms of rational individuals communicating unambiguously in a marketplace of other rational actors, perhaps unintentionally, has led to the growth of an alternative, if minority strand of ethical reasoning, that advances a "buyer beware" principle: everyone must act defensively to protect himself or herself against potential infection and never assume that potential sexual partners know their sero-status or will clearly disclose it if it is known. This buyer-

34 Adam, "Infectious Behaviour" (2006) 4 Social Theory and Health 168.

35 Barry Smart. Economy, Culture and Society 7 (Buckingham, UK: Open University Press). 36 Mark Davis. "HIV prevention rationalities and serostatus in the risk narratives of gay men" (2002) 5 Sexualities 281. 
beware view occurs in a social environment where HIV-positive people experience strong disincentives to disclose in the face of potential rejection or discrimination once their sero-status is known. Finally, examination of the social consequences of this judicial policy raises questions about the viability of relying on, and legally enforcing, disclosure as a leading method of HIV prevention, especially when most practical, day-to-day HIV prevention occurs when safer sex is practised consistently regardless of disclosure. 